Política, comunicação e o contexto político atual na Venezuela e no Brasil (Entrevista com David Smilde)

[Politics, communication and current political contexts in Venezuela and Brazil (Interview with David Smilde)]

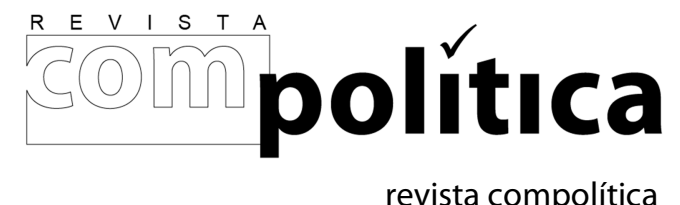

revista compolítica 2016, vol. 6(1)

compolitica.org/revista

ISSN: 2236-4781

DOI: 10.21878/compolitica.2016.6.1.261

(O) Open Access Journal

\title{
Juliana Gagliardi
}

Universidade Federal Fluminense

[Fluminense Federal University]

\section{Fernanda Nalon Sanglard}

Universidade do Estado do Rio de Janeiro

[Rio de Janeiro State University] 


\section{Política, comunicação e o contexto político atual na Venezuela e no Brasil (Entrevista com David Smilde)}

Juliana GAGLIARDI

Fernanda SANGLARD

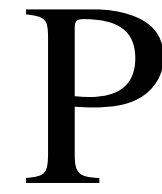

rofessor do Departamento de Sociologia da Tulane University, em Nova Orleans (EUA), David Smilde é um dos pesquisadores contemporâneos norte-americanos mais reconhecidos pelos estudos sobre a América Latina, especificamente sobre a Venezuela. Editor-chefe da revista científica Qualitative Sociology e integrante sênior do Escritório de Washington para a América Latina (Washington Office on Latin America - WOLA), Smilde também é autor dos livros Reason to Believe (lançado em português como “Razão para crer”), Venezuela's Bolivarian Democracy (organizado em parceria com Daniel Hellinger), Religion on the Edge (organizado juntamente com Courtney Bender, Wendy Cadge e Peggy Levitt) e Protesta y Cultura en Venezuela (com Margarita López Maya e Keta Stephany).

Preocupado em compreender as dimensões sociais do bolivarianismo ${ }^{1}$ na Venezuela, Smilde promove - em suas obras e também nas disciplinas que ministra - o alargamento do olhar sobre questões políticas, econômicas e culturais da América Latina. Quebrando paradigmas e preconceitos, o pesquisador propõe romper com as interpretações majoritárias e fortemente ideológicas que ganham espaço nos veículos noticiosos para analisar as políticas desenvolvidas pelo chavismo. ${ }^{2}$ Apesar de crítico ao controle de mídia exercido como ferramenta política na Venezuela, Smilde reconhece que "Chávez investiu pesado nos meios de comunicação" e, "para o bem ou para o mal", brinca o pesquisador, contribuiu para abalar a alta concentração de mídia que era vigente naquele país.

Nesta entrevista para a Compolítica, Smilde aborda temas como a "virada à esquerda" e o recente fortalecimento dos governos de direita na América Latina, que culminaram com a impopularidade e o processo de impeachment da presidente Dilma Rousseff. Tomando como ponto de partida o campo da comunicação e a concentração midiática na América Latina, a proposta é discutir ações políticas contemporâneas, o atual cenário de crise em alguns países e proporcionar a desconstrução de pontos de vista simplistas sobre a 
complexa arena de disputa que envolve a política latino-americana. O professor fala também das relações entre mídia e política, sobre a participação da religião nos contextos sociais da Venezuela e dos Estados Unidos e traça um panorama sobre os avanços e fracassos do governo de Hugo Chávez e de seu sucessor, Nicolás Maduro.

O resultado desta entrevista é uma oportunidade para os brasileiros que ainda não conhecem a produção de David Smilde e que se interessam por compreender melhor o jogo político dos países latinos, que tem no espaço midiático um de seus alicerces.

Um de seus últimos livros, organizado em coautoria com Daniel Hellinger Venezuela's Bolivarian Democracy: Participation, Politics and Culture under Chávez (Duke, 2011) -, observa as formas de participação dos cidadãos na Venezuela. Quatro capítulos do livro abordam as relações entre sociologia, comunicação e democracia (é o caso de "Catia sees you", "Radio Bemba in an age of electronic media", "Defying the Iron of Oligarchy II: Debating Democracy Online in Venezuela" and "Venezuela's Telenovela"). Como o senhor explica a importância da mídia na política contemporânea na Venezuela?

Antes de Hugo Chávez, a Venezuela era caracterizada pela concentração de mídia típica dos países da América Latina. Um punhado de interesses capitalistas privados controlava a grande maioria dos veículos de comunicação. Após alguns anos, quando Chávez mudou a estratégia de simplesmente tentar "aprofundar" a democracia política para tentar "expandir" a democracia nas esferas social, econômica e cultural, a mídia, juntamente com outras vertentes do grande capital, virou-se contra ele. E, na ausência de efetiva oposição dos partidos políticos, a mídia assumiu o papel de agregação política exercido usualmente pelos partidos. No período de grave crise entre 2002 e 2004, a mídia foi um jogador partidário ativo. Os veículos de comunicação facilitaram os protestos e experimentaram criar um senso de caos. Um canal privado, a Globovisión, costumava cobrir as manifestações colocando trilha sonora dramática de fundo e movendo a câmera para trás e para frente para promover aspecto de sentimento vertiginoso. E, é claro, como documentado no filme "A revolução não será televisionada", a grande mídia comercial 
participou ativamente cobrindo o fato de que um golpe havia ocorrido em 11 de abril de 2002, mas não cobriu as manifestações de rua que dele resultaram.

Como consequência da existência dessa hegemonia de mídia, o governo Chávez investiu pesado nos meios de comunicação, atualizando o canal estatal Venezolana de Televisión e criando muitos outros. Ele também investiu em programas de televisão e rádio comunitários, páginas na internet, outdoors e propaganda. A mídia realmente se transformou em uma peça-chave do governo Chávez. E isso não era apenas para contrabalançar a hegemonia da mídia existente. Em contraste com os casos de Lula da Silva e Evo Morales, Hugo Chávez não chegou ao poder com o apoio de um partido existente ou movimento social. Assim, ele não teve um caminho natural para agregar e articular seus seguidores. Uma forma de abordar este déficit foi através dos meios de comunicação.

Na situação atual, é notável que, com condições de pobreza como as de 2015, o PSUV ainda tenha obtido $41 \%$ nas eleições legislativas em dezembro e Maduro entre $20 \%$ e $30 \%$ de suporte. Você pode comparar com o Brasil, onde as condições não eram tão difíceis assim e a popularidade de Dilma Rousseff decaiu à casa de um dígito. Isto se deve, em grande parte, ao grande aparato de mídia do governo venezuelano, que, em algumas partes do país, possui a única estação de televisão que as pessoas podem assistir.

O senhor tem pesquisado sobre a Venezuela nas últimas duas décadas. A primeira vitória de Chávez, em 1998, afetou muito a América Latina e a forma que a região é vista pelo mundo. Como o senhor explica o crescimento e o sucesso do "chavismo" por tanto tempo?

Chávez subiu ao poder depois de uma década muito difícil de reforma neoliberal e austeridade na Venezuela. Por uma década as pessoas foram informadas de que teriam que cuidar de si mesmas, porque o governo não tinha os recursos para fornecer a elas. Hugo Chávez surgiu junto com uma mensagem populista dizendo às pessoas que a Venezuela era rica em recursos que estavam "escoando pelo ralo" com a elite conspiratória. Ele prometeu que, se fosse eleito presidente, usaria a riqueza mineral e do 
petróleo venezuelano para cuidar das pessoas, e abriria a democracia à participação popular. Ele fez ambas as coisas. A Constituição de 1999 promoveu novas instituições para participação popular na governança. Chávez também trabalhou imediatamente para ressuscitar a Opep (Organização dos Países Exportadores de Petróleo) e liderou o aumento do preço do petróleo em seu primeiro ano de mandato. Após enfrentar um esforço orquestrado contra sua presidência em 2004, ele comandou um período importante de crescimento econômico e de declínio dramático da pobreza e desigualdade entre 2004 e 2012. Ele fez isso com uma mensagem nacionalista e direcionada às maiorias pobres e excluídas. Isso não é algo que as pessoas vão esquecer facilmente. Ele fez os venezuelanos médios sentirem como se pertencessem aquilo e tivessem um futuro.

Durante o período de Maduro temos assistido à lenta decadência do chavismo, com Maduro se posicionando basicamente à esquerda do modelo Hugo Chávez no tato e adiando ajustes e reorientações necessários. Ninguém no chavismo tem o carisma de Chávez e esse é um projeto que foi desenvolvido ao redor de uma figura carismática. A menos que haja algum tipo de reorientação significativa, parece provável que o chavismo não permaneça no poder por muito mais tempo.

Uma das muitas diferenças entre os governos Chávez, na Venezuela, e do Partido dos Trabalhadores (PT), no Brasil, diz respeito à relação com a mídia. Na Venezuela, leis foram criadas para limitar o poder da mídia, contudo isso foi criticado como medida autoritária. No atual contexto político no Brasil, onde isso não aconteceu, pesquisadores discutem sobre a necessidade de regulação da mídia para enfrentar a intensa concentração e oferecer pontos de vista plurais. Nesse contexto, como o senhor entende que as relações entre governo e mídia podem afetar a democracia?

Isso é verdade, para o bem e para o mal. O fato de o governo Dilma ter se tornado tão impopular tão rápido, apesar dos desafios políticos e econômicos relativamente modestos - ao menos se comparados à Venezuela -, mostram quão ágil pode atuar a mídia para complicar um projeto político que ela não goste. Isso sugere que projetos de esquerda 
transformadores precisam passar a regulações e projetos que democratizem a mídia e reduzam o controle do grande capital sobre as notícias e as informações que as pessoas recebem.

Contudo, eu não acho que a Venezuela seja um bom exemplo. Aqui o controle sobre a mídia tem se tornado uma ferramenta política para promover autocensura. Talvez pior, televisões estatais, rádios e jornais impressos têm pouca ou nenhuma autonomia, como existe, por exemplo, na BBC no Reino Unido. Como resultado, eles agem a reboque da linha do governo e não servem de instâncias críticas. Essa carência de abordagem crítica e debate é uma das razões para a atrofia e decadência do projeto político chavista.

Muitos autores chamaram o movimento político que levou muitos líderes genericamente identificados como representantes da esquerda a governarem países latino-americanos como "virada à esquerda" (Left Turn). Alguns exemplos são Lula, no Brasil, Chávez, na Venezuela, os Kirchners, na Argentina, e Morales, na Bolívia. Recentemente, no entanto, a esquerda tem sofrido duros golpes: O sucessor de Cristina Kirchner perdeu as eleições, Dilma Rousseff enfrenta altas taxas de impopularidade e o processo de impeachment, Maduro teve significativa perda de poder nas eleições do Congresso venezuelano. Qual é a sua avaliação sobre isso? Acredita que um novo movimento, como uma "virada à direita", pode emergir?

Eu penso que é cedo para falar de uma virada à direita. Macri venceu a presidência da Argentina. Temer obteve a Presidência no Brasil. Mas não está claro quanto poder seus governos terão para realmente forjar uma nova direção. Isso teve recepção fria entre os líderes regionais e a legitimidade vem sendo questionada dentro do Brasil. Por outro lado, Morales e Correa ainda são populares em seus países, mesmo que não concorram à reeleição, e Bachelet e Vasquez retornaram à presidência no Chile e no Uruguai. A esquerda definitivamente promoveu um boom de commodities para o sucesso na década passada e os operadores históricos também enfrentam desafios quando a economia declina. Eu acho que nós provavelmente assistimos ao fim, ao menos por enquanto, de 
algo da crescente retórica da esquerda. Mas nós não vimos o fim das demandas das pessoas para a inclusão social, cultural e econômica. Países que tentam retornar aos pacotes de ajustes estruturais neoliberais da década de 1990 provavelmente terão tempos difíceis. Penso que as pessoas estão demandando mais accountability dos líderes eleitos e que a esquerda tem que fazer trabalho melhor, controlando a corrupção, se ela espera consolidar os ganhos da última década e meia.

Na América Latina existe um conceito-chave nas discussões sobre política, que é o populismo, e ele assume formas diferentes do populismo europeu. Em entrevista recente ${ }^{3}$, Chantal Mouffe, falando sobre o populismo e a esquerda, disse que há uma dimensão populista necessária na democracia. O que o senhor diz sobre isso?

Para mim, populismo não é uma palavra ruim. Eu acho que democracias deveriam favorecer as maiorias pobres em suas políticas. Entretanto, isso pode ser feito por meio de algumas políticas econômicas. $\mathrm{Na}$ Venezuela, eu penso que era evidente por muitos anos que as políticas de Hugo Chávez eram efetivas na redução da pobreza e da desigualdade em curto prazo, mas não sustentável em longo prazo. Eu acredito que as políticas de Lula da Silva foram menos dramáticas do que as de Chávez, mas mais sustentáveis para o futuro.

O populismo é, de fato, um conceito de definição imprecisa. No Brasil, pesquisadores têm tentado lidar com ele de forma mais ampla nas últimas décadas, negando a visão de que é uma característica simplesmente negativa e a manipulação como única chave para explicação. Contudo, no senso comum e especialmente em meio à grande imprensa, ele continua a ser retratado como aspecto bastante negativo que caracterizaria governos de esquerda em geral. Por que esse descompasso continua? E, neste contexto, que papel a mídia desempenha na sociedade? 
A América Latina é a região mais desigual do mundo e a elite política e econômica tem lutado sempre para manter o controle de formações sociais e políticas tênues que mantém as massas do povo na pobreza. Esses líderes desafiariam essa situação ao longo do último século ou de modo geral fizeram isso por meio de algum tipo de ideologia populista ou mobilização. Com isso quero falar de uma ideologia que descreve os pobres como o autêntico "povo" da nação e sugere que a sua situação se deve a uma elite conspiradora. Esta é uma ideologia poderosa e trouxe alguns desses líderes ao poder. Alguns esforços de redistribuir a riqueza obtiveram sucesso. Outros, foram contraprodutivos ou destrutivos. Todos eles desafiaram o status quo e foram rotulados como irresponsáveis, manipuladores e malevolentes por setores da elite. Algumas vezes isso é certo, muitas vezes, é errado. O que é necessário é atravessar os retratos ideológicos de autointeresse dados pela mídia sobre líderes a favor dos pobres, para, em vez disso, analisar as suas políticas, ver o que funciona e o que não funciona.

Desde o último ano (2015), nós assistimos à emergência de intensa polarização política no Brasil. Tal polarização é também uma importante característica da política venezuelana. Quais são as diferenças entre esses dois contextos?

Eu penso que a polarização é similar em cada contexto, mas diferente em intensidade. Hugo Chávez buscou ativamente polarizar, porque ele sabia que se ele pudesse fazer isso em uma base de classe, ele ganharia cada eleição. A oposição da Venezuela alegremente caiu vez e outra nessa armadilha, porque eles estavam sempre convencidos de que eles eram maioria. Lula da Silva foi mais conciliatório e fez mais concessões ao grande capital. Isso reduziu a polarização no Brasil em comparação com a Venezuela.

Nesse contexto de polarização, a presidente Dilma Rousseff se tornou realmente impopular se considerarmos a popularidade de seu mandato anterior ou do governo Lula. Em vez disso, na Venezuela, apesar das condições políticas e econômicas difíceis, Nicolás Maduro ainda parece ser mais popular em comparação. Como explica este quadro? 
Como eu mencionei, isso acontece em grande parte em razão do significativo controle sobre a mídia que o governo Maduro impôs. Isso também se deve à memória de Hugo Chávez e ao fato de que a oposição venezuelana não encaminhou nenhum projeto ideológico ou político alternativo que engajasse as pessoas. Uma vez que eles mesmos são muito divididos, tendem a permanecer abstratos e a ganhar apoio a partir dos altos índices de rejeição ao chavismo.

Há alguns anos um de seus livros foi lançado em português - "Razão para crer: agência cultural no movimento evangélico latino-americano" (Eduerj, 2012). Esse volume - sobre igrejas pentecostais, pobreza, violência e mudanças culturais em Caracas (Venezuela) - inspirou uma questão: Quão intimamente se relacionam religião e política na América Latina?

Isso varia um pouco de país para país. $\mathrm{Na}$ Venezuela, desde o início, a hierarquia católica tem sido uma das fontes mais consistentes de oposição ao chavismo. Contudo, os evangélicos, em sua maior parte, apoiaram o chavismo nos seus primeiros oito anos ou mais. Mesmo agora, o nome do Vaticano é frequentemente mencionado como um possível facilitador do diálogo entre o governo e a oposição.

De modo geral, a América Latina é bastante religiosa e ideologias, instituições e líderes religiosos agregam os sentimentos e as perspectivas das pessoas e têm influência significativa. É de se esperar que isso tenha influência na política de cima para baixo. A hierarquia católica tem exercido por muito tempo uma influência conservadora, ainda que a Teologia da Libertação e os sacerdotes liberacionistas tenham sido algumas das fontes mais importantes de movimentos sociais progressistas e de mudança social. Os evangélicos estão cada vez mais envolvidos na política e com frequência têm perspectivas conservadoras - como nós estamos vendo agora no Brasil. Mas, no nível das bases, os grupos evangélicos e pentecostais são com frequência a única forma de sociedade civil disponível às pessoas e podem ter um impacto local importante dando a essas pessoas um caminho para confrontar a violência e a injustiça nos seus contextos locais. 


\section{O senhor acredita que a relação entre política e religião é mais forte na América}

\section{Latina do que nos Estados Unidos?}

Eu acredito que seja diferente, mas não necessariamente mais forte. Nos Estados Unidos não há uma religião estabelecida, mas tendências religiosas, como ser evangélico ou cristão conservador, que têm profundos impactos sobre as tendências dos eleitores. George W. Bush era evangélico e isso teve um grande impacto na visão dele do que o governo era e do papel dos Estados Unidos no mundo. Ele teve um senso de certeza moral que o levou a ser muito irreflexivo no que diz respeito a suas ações e ele superestimou significativamente o quanto o mundo precisava da orientação dos Estados Unidos. Eu acredito que ele nunca teria respondido ao 11 de setembro - invadindo o Afeganistão e o Iraque e lançando a "guerra ao terror" — se ele mesmo não fosse profundamente religioso e cristão.

Na América Latina, as instituições religiosas são muito mais importantes. Na maior parte dos países a hierarquia católica exerce poder político significativo e os sacerdotes liberacionistas, nas lutas progressistas por justiça, e os partidos evangélicos têm ganhado cada vez mais poder. Nos Estados Unidos, a ideologia religiosa é mais importante. Não há partidos religiosos significativos, por exemplo, e poucas instituições religiosas têm poder político significativo.

\section{Agradecimentos e Observações}

Fernanda Sanglard e Juliana Gagliardi cursaram a disciplina "Estado e sociedade na América Latina", oferecida pelo professor David Smilde, na Tulane University (New Orleans, Louisiana, EUA), em 2015, enquanto realizavam estágio doutoral no exterior com financiamento da Capes (processos 6435-15-7 e 9554/14-9), o que possibilitou a realização desta entrevista.

\section{Notas}

1 O termo bolivarianismo deriva do sobrenome de Simón Bolívar, general que, no século XIX, liderou movimentos de independência na Venezuela, na Colômbia, no Equador, no Peru e na Bolívia. Bolívar nutria o ideal de estreitar as relações entre os países recém-independentes, excolônias espanholas. A apropriação do termo por Hugo Chávez e por outros presidentes 
contemporâneos da América Latina, como Evo Morales, fez com que fosse vinculado atualmente a movimentos de esquerda que questionam o neoliberalismo no continente.

2 A ascensão de Hugo Chávez como líder político na Venezuela, no final dos anos 1990, fundou um modelo de governo que ficou conhecido como chavismo. De acordo com Smilde (2015), Chávez foi o primeiro a convencer a América Latina de que um candidato de esquerda poderia chegar ao poder via eleições democráticas, governar pela esquerda e sobreviver ao embate com as elites. Ainda segundo Smilde, foi Chávez quem mostrou à região que as políticas neoliberais poderiam ser desafiadas e a atenuação da pobreza e da desigualdade, priorizadas. Outras características são ainda, de modo geral, atribuídas ao movimento chavista, como o intenso uso dos meios de comunicação e o petróleo como pilar econômico de governo.

3 "Hay una necesaria dimensión populista en democracia". El País, 19 de abril de 2015. Disponível em:

<http://politica.elpais.com/politica/2015/04/17/actualidad/1429290307_967426.html>.

\section{Referências}

BENDER, Courtney; CADGE, Wendy; LEVITT, Peggy; SMILDE, David (eds). Religion on the Edge: Decentering and Recentering the Sociology of Religion. New York: Oxford University Press, 2012.

JEFFREY, Rubin; SMILDE, David; JUNGE, Benjamin (eds). Lived Citizenship and Lived Religion in Latin America's Zones of Crisis. Latin American Research Review, 2014. p.7-26. Disponível em: <https://lasa.international.pitt.edu/LARR/prot/fulltext/vol49noSI/49-SI_726_Rubin-Smilde-Junge.pdf $>$. Acesso em: 11 jun. 2016.

SMILDE, David; HELLINGER, Daniel (eds). Venezuela's Bolivarian Democracy: Participation, Politics, and Culture under Chávez. Durham NC: Duke University Press, 2011.

SMILDE, David. Razão para crer: agência cultural no movimento evangélico latino-americano. Trad. Maria Beatriz de Medina. Rio de Janeiro: EdUERJ, 2012. The end of chavismo? Current History, v.114, n.769, p. 49-55, 2015.

\section{As autoras}

Juliana Gagliardi é doutoranda em Comunicação e mestre em Comunicação pela Universidade Federal Fluminense. jugagliardi@gmail.com

Fernanda Nalon Sanglard é doutoranda em Comunicação pela Uerj e mestre em Comunicação pela UFJF. nandanalon@yahoo.com.br 